\begin{tabular}{|c|c|}
\hline Title & $\begin{array}{l}\text { Channeling Exciton Migration into Electron Transfer in Formamidinium Lead Bromide Perovskite } \\
\text { Nanocrystal/Fullerene Composites }\end{array}$ \\
\hline Author(s) & Nair, Vijay akumar C.; Muthu, Chinnadurai; Rogach, A ndrey L.; Kohara, Reiko; Biju, V asudevanpillai \\
\hline Citation & $\begin{array}{l}\text { A ngewandte chemie international edition, 56(5), } 12141218 \\
\text { https://doi.org/10.1002/anie.201610070 }\end{array}$ \\
\hline Issue Date & 2017-01-24 \\
\hline Doc URL & http:/hdl.handle.net/2115/68017 \\
\hline Rights & $\begin{array}{l}\text { This is the peer reviewed version of the following article: [V . C. Nair, C. Muthu, A. L. Rogach, R. Kohara, V . Biju, } \\
\text { A ngew. Chem. Int. Ed. 2017, 56(5), 1214-1218.], which has been published in final form at } \\
\text { http://dx.doi.org/10.1002/anie.201610070. This article may be used for non-commercial purposes in accordance with } \\
\text { Wiley Terms and Conditions for Self-A rchiving. }\end{array}$ \\
\hline Type & article (author version) \\
\hline File Information & Biju_Angew_2016.pdf \\
\hline
\end{tabular}

Instructions for use 


\title{
Channeling Exciton Migration into Electron Transfer in Formamidinium Lead Bromide Perovskite Nanocrystal / Fullerene Composites
}

\author{
Vijayakumar C. Nair, ${ }^{[\mathrm{a}, \mathrm{b}]} *$ Chinnadurai Muthu, ${ }^{[\mathrm{b}]}$ Andrey L. Rogach,${ }^{[\mathrm{c}]}$ Reiko Kohara, ${ }^{[\mathrm{a}]}$ \\ Vasudevanpillai Biju ${ }^{[\mathrm{a}, \mathrm{d}] *}$
}

\begin{abstract}
Hydrophobic-capped nanocrystals of formamidinium lead bromide $\left(\mathrm{FAPbBr}_{3}\right)$ perovskite (PNC) show bright and stable fluorescence in the solution and thin film states. When compared with isolated PNCs in a solution, close-packed PNCs in a thin film show extended fluorescence lifetime (ca $4.2 \mu \mathrm{s})$, which is due to hopping or migration of photogenerated excitons among PNCs. Both fluorescence quantum efficiency and lifetime decrease in a PNC thin film doped with $\mathrm{C}_{60}$, which is attributed to channeling of exciton migration into electron transfer to fullerenes. On the other hand, quenching of fluorescence intensity of a PNC solution isn't accompanied by any change in fluorescence lifetime, indicating static electron transfer to $\mathrm{C}_{60}$ adsorbed onto the hydrophobic surface of individual PNCs. Exciton migration among close-packed PNCs and electron transfer to $C_{60}$ places $\mathrm{C}_{60}$-doped $\mathrm{PNC}$ thin films among cost-effective antenna systems for solar cells.
\end{abstract}

Metal halide perovskites have emerged into a class of promising materials for top 10 future technologies such as solar cells, which is owing to their distinctive optical and electronic properties and cost-effective production. Recent reports show solar photon to electricity conversion efficiency of perovskite solar cells exceeds $20 \%$, keeping the upper limit open to further research, which, on the other hand, hits the roof for silicon photovoltaics. ${ }^{1}$ The commendable optical and electronic properties of perovskites make them also useful for several other optical and electronic devices such as light-emitting diodes, lasers, photodetectors, sensors and memory devices. ${ }^{2}$ Besides the straightforward preparation and applications of perovskite films, very recently, hybrid PNCs have become popular with great research interest and technological relevance. ${ }^{3}$ PNCs exhibit intense fluorescence due to quantum confinement effect

[a] Dr. V. C. Nair, R. Kohara, Prof. V. Biju

Research Institute for Electronic Science and

Graduate School of Environmental Science, Hokkaido University

N20, W10, Sapporo, Hokkaido 001-0020, Japan

Email: biju@es.hokudai.ac.jp

[b] Dr. V. C. Nair, C. Muthu

Photosciences and Photonics Section, CSIR-National Institute for Interdisciplinary Science and Technology, Thiruvananthapuram 695 019 and Academy of Scientific and Innovative Research (AcSIR), New Delhi 110 001, India

E-mail: cvijayakumar@niist.res.in

[c] Prof. A. L. Rogach

Department of Physics and Materials Science \& Centre for

Functional Photonics (CFP)

City University of Hong Kong

83 Tat Chee Avenue, Kowloon, Hong Kong SAR

[d] Health Research Institute, National Institute of Advanced Industrial Science and Technology (AIST), Takamatsu 761-0395, Japan which is easily tuned by band-gap engineering and chemical composition $^{4}$ and show great promise when compared with perovskite films. $^{5}$

Addressing fundamental photophysical properties of PNCs in combination with other materials calls for exploration, and is expected to further the applications of PNCs in LEDs and solar cells. Photoinduced electron transfer (PET) is the fundamental process in natural and artificial photosynthesis. ${ }^{6}$ Recently, electron transfer studies in perovskite-based electron donoracceptor systems receive great momentum, which is owing to their potential application in solar cell technology. For example, Grätzel et al. revealed ultrafast electron transfer from photoexcited perovskite to mesoporous titanium dioxide, leading to efficient charge separation. ${ }^{7}$ In a subsequent report, Sunderström et al. pinpointed the time scale and mechanism of electron transfer from perovskite to an organic acceptor molecule. ${ }^{8}$ PNCs have been explored in electron transfer to classical acceptors such as benzoquinone, ${ }^{9}$ phenothiazine ${ }^{9}$ and perylene. ${ }^{10}$ Recent studies by Huang et al. and Sargent et al. show improved stability and photocurrent response for solar cells based on $\mathrm{C}_{60}$-layered perovskites, which are attributed to passivation of surface defects and removal of grain boundaries in perovskites by $\mathrm{C}_{60 .}{ }^{11,12}$ In contrast with these reports, in the current work, we evaluate the effect of $\mathrm{C}_{60}$ on the fluorescence of $\mathrm{FAPbBr}_{3} \mathrm{PNCs}$ in solutions and thin films. Here, $\mathrm{C}_{60}$ acts as an electron acceptor and efficiently quenches the fluorescence of photoactivated PNCs isolated in a solution or closely-packed in a film. In the latter case, electron transfer to $\mathrm{C}_{60}$ competes with the migration of photo-generated excitons, which results in a drastic decrease of the fluorescence quantum efficiency and lifetime of PNC. Thus, we reveal channeling of exciton migration in closely-packed PNCs in a thin film into electron transfer to $C_{60}$ doped in the film.

We investigate steady-state and time-resolved fluorescence of formamidinium lead bromide $\left(\mathrm{FAPbBr}_{3}\right)$ PNCs in solutions and films with or without $\mathrm{C}_{60}$. $\mathrm{FAPbBr}_{3}$ PNCs were prepared as follows. Octylammonium bromide was dissolved in a mixture of oleic acid and octadecene at $80{ }^{\circ} \mathrm{C}$, which was followed by addition of formamidinium bromide and lead (II) bromide dissolved in $\mathrm{N}, \mathrm{N}$-dimethylformamide. The addition of acetone to the above reaction mixture precipitates PNCs which were separated by ultracentrifugation. Dry powders were re-dispersed in toluene and used in fluorescence measurements. Details of preparation of PNC and samples are provided in the Supporting Information. The transmission electron microscope (TEM) images reveal that the above synthesis provides mostly spheroid PNCs with an average diameter of $5 \mathrm{~nm}$ (Figure 1a). TEM image of a thin film sample is 

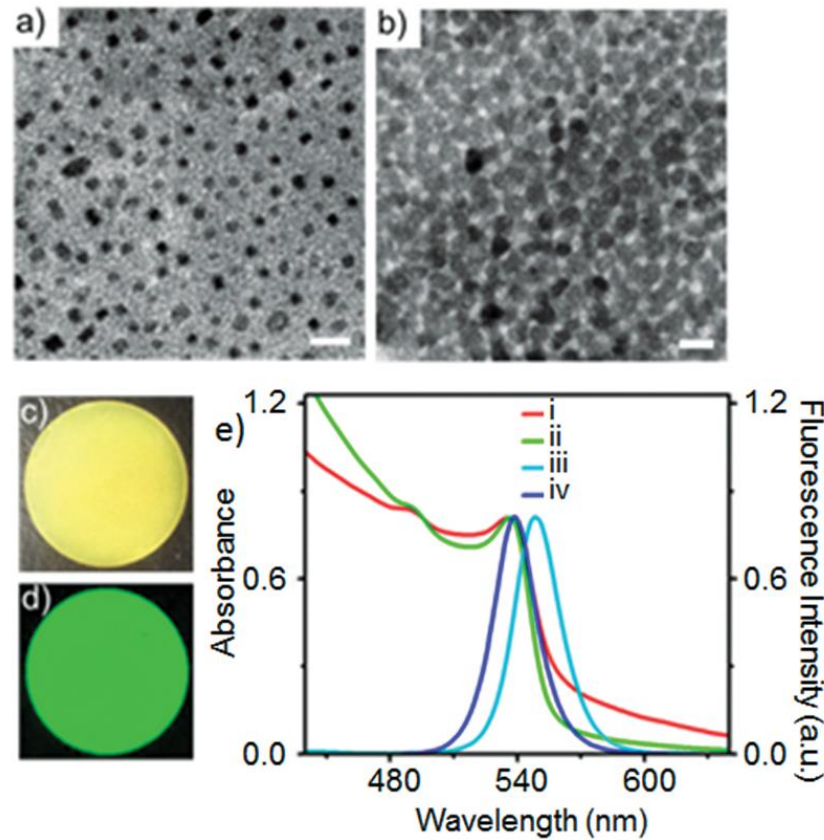

Figure 1. (a,b) TEM images of (a) isolated $\mathrm{FAPbBr}_{3} \mathrm{PNCs}$ and (b) a thin film of PNCs (scale bars: $20 \mathrm{~nm}$ ). (c,d) Photographs of a PNC thin film under (c) room light and (d) UV light. (e) Absorption (i,ii) and fluorescence (iii,iv) spectra of (ii,iv) a PNC solution $(0.1 \mathrm{mg} / \mathrm{mL}$ in toluene) and (i,iii) a PNC thin film. Fluorescence spectra were recorded by exciting the samples at $400 \mathrm{~nm}$.

also shown in Figure 1b, which indicates uniform distribution of PNCs in the film. The powder, solution and film of PNC are yellow in color with an intense green fluorescence (Figure 1c and 1d). The absorption and fluorescence spectra of PNCs in a solution and a film are shown in Figure 1e. In the solution, PNCs absorb light broadly in the UV-visible region with the sharp absorption band at ca $537 \mathrm{~nm}$. The fluorescence is intense (quantum yield $=$

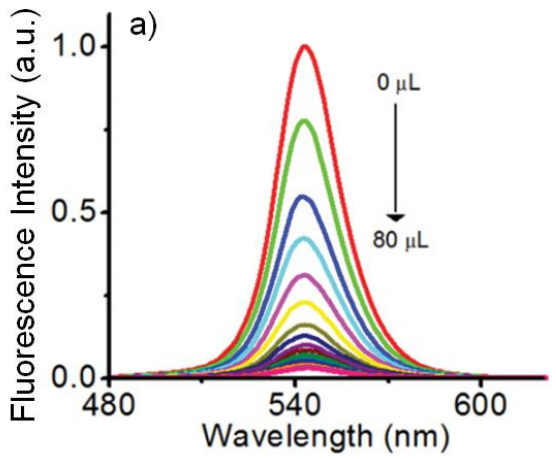

b)

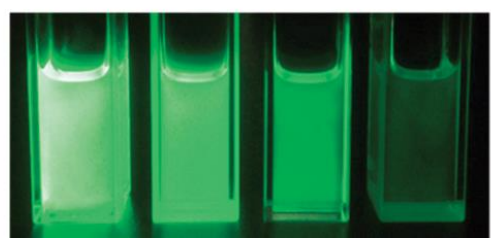

Figure 2. (a) Fluorescence spectra of a $\mathrm{FAPbBr}_{3} \mathrm{PNC}$ solution supplemented with different concentrations $\left(0\right.$ to $4 \mu \mathrm{M}$ ) of $\mathrm{C}_{60}$ (concentration of $\mathrm{FAPbBr}_{3}: 0.1$ $\mathrm{mg} / \mathrm{mL}, \lambda_{\text {ex }}=400 \mathrm{~nm}$ ). (b) Photographs of PNC solutions supplemented with different concentrations of $\mathrm{C}_{60}$ (from left to right; $0,0.5,1.5$ and $4 \mu \mathrm{M}$ ).

0.72) and sharp with a narrow (24 $\mathrm{nm})$ full-width at half maximum. When compared with the PNC solution, the fluorescence band of the film is red-shifted from 538 to $548 \mathrm{~nm}$ (Figure 1e). The red-shift is attributed to energy transfer from smaller to larger crystals in the close-packed film sample. Interestingly, the fluorescence remained intense (quantum yield: $60 \%$ ) and sharp in the films state, with a spectral full-width at half maximum of $25 \mathrm{~nm}$.

To test electron transfer from $\mathrm{FAPbBr}_{3} \mathrm{PNCs}$, we selected fullerene $\left(\mathrm{C}_{60}\right)$ as the electron acceptor. At first, we recorded the fluorescence spectrum of a PNC solution $(0.1 \mathrm{mg} / \mathrm{mL}$ in toluene) and to which $\mathrm{C}_{60}(1 \mathrm{mg} / \mathrm{mL})$ dissolved in toluene was added in $0.5 \mu \mathrm{M}$ portions. The addition of $\mathrm{C}_{60}$ resulted in continuous quenching of the PNC fluorescence, indicating efficient electron transfer from perovskite to $\mathrm{C}_{60}$ (Figure 2a). The initial quenching was remarkably large, and the rate at which $\mathrm{C}_{60}$ quenched the fluorescence of PNC decreased further with increase in the concentration of $\mathrm{C}_{60}$. As the concentration of $\mathrm{C}_{60}$ was increased up to $4 \mu \mathrm{M}$ (2.8 wt\% with reference to PNC), the fluorescence of PNC was quantitatively (ca $98 \%$ ) quenched (Figure $2 a$ ), which is attributed to efficient electron transfer from photoactivated PNC to $\mathrm{C}_{60}$. Visual changes to the fluorescence are clearly seen in the photographs of PNC solutions supplemented with different concentrations (0 to $4 \mu \mathrm{M})$ of $\mathrm{C}_{60}$ (Figure 2b). These observations suggest that the static quenching of PNC fluorescence dominant at lower concentrations of $\mathrm{C}_{60}$ shifts into dynamic quenching at higher concentration of $\mathrm{C}_{60}$. In other words, the quenching does not follow the theoretical 1:1 ratio at higher concentrations of $\mathrm{C}_{60}$.

We obtained additional insight into electron transfer from $\mathrm{PNC}$ to $\mathrm{C}_{60}$ from time-resolved fluorescence data. Fluorescence decay profiles of a solution of PNCs in toluene without or with different concentrations of $\mathrm{C}_{60}$ were examined by excitation of the samples with $400 \mathrm{~nm}$ fs laser pulses. Interestingly, the fluorescence lifetime of the samples remained essentially intact $(1.3 \mu \mathrm{s})$ by the concentration $(0.5$ to $4 \mu \mathrm{m})$ of $\mathrm{C}_{60}$ (Figure $3 \mathrm{a}$ ); whereas, the number of photons emitted by the sample linearly decreased with increase in the concentration of $\mathrm{C}_{60}$, indicating the quenching of photo-excited PNC by $\mathrm{C}_{60}$. Correlation between emitted photons and fluorescence lifetime of PNC is presented in the photocount-wavelength-lifetime 3D images (Figure 3b,c) The intact fluorescence lifetime, which is accompanied by the monotonous decrease in the number of emitted photons indicates static quenching of the excited state of PNC by $\mathrm{C}_{60}$. In other words, the excited state of PNC is deactivated by electron transfer to $\mathrm{C}_{60}$, whereas residual fluorescence at a given concentration of $\mathrm{C}_{60}$ represents $\mathrm{PNCs}$ without any adsorbed $\mathrm{C}_{60}$. In other words, a temporal decrease of fluorescence quantum efficiency without any notable change to the fluorescence lifetime indicates adsorption of $\mathrm{C}_{60}$ onto more and more $\mathrm{FAPbBr}_{3}$ PNCs, the surface of which are capped with hydrophobic ligands.

To understand the nature of fluorescence quenching by $\mathrm{C}_{60}$, PNC solutions supplemented with different concentrations of $\mathrm{C}_{60}$ were processed into thin films by drop-casting, and fluorescence intensities and decay profiles of the films were recorded. We 
observed monotonous decrease of both fluorescence lifetime and intensity of PNC films with increase in the doping density of $\mathrm{C}_{60}$ (Figure 3d), an observation completely different from the $\mathrm{C}_{60^{-}}$ independent fluorescence lifetime of PNC in the solution phase. The corresponding photocount-wavelength-decay 3D images collected from film samples with and without $\mathrm{C}_{60}$ are shown in

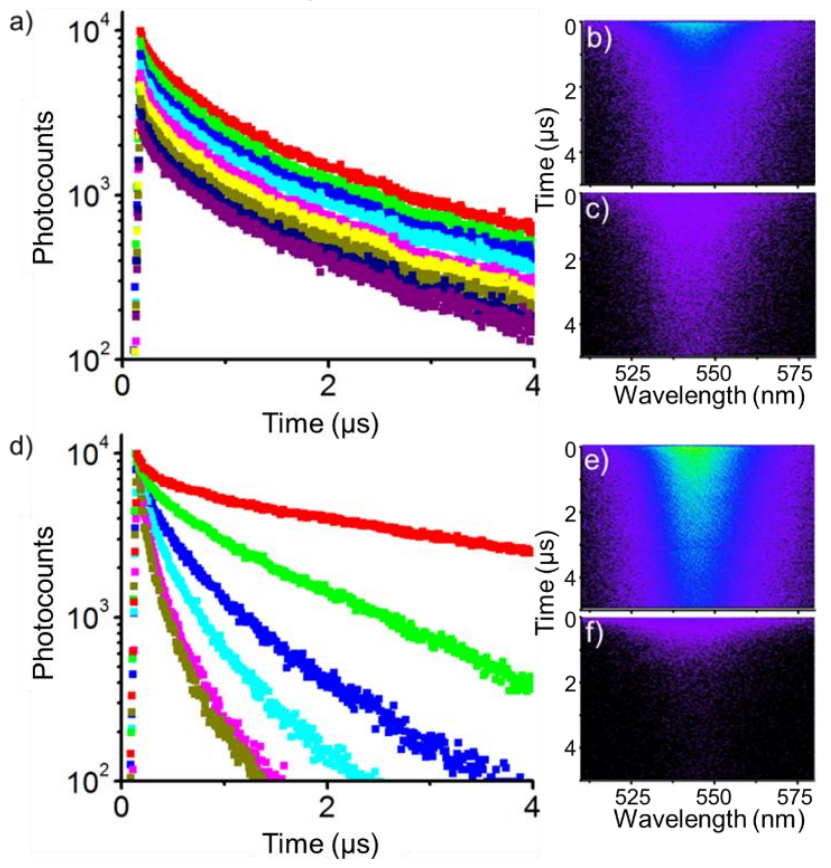

Figure 3. Fluorescence decay profiles of $\mathrm{FAPbBr}_{3}$ PNCs (a) dissolved in toluene and supplemented with different concentrations of $\mathrm{C}_{60}$ (top to bottom: 0 to $4 \mu \mathrm{M} @ 0.5 \mu \mathrm{M})$, (d) in thin films prepared from PNC solutions supplemented with different concentrations of $C_{60}$ (top to bottom: 0 to $4 \mu \mathrm{M} @$ $0.5 \mu \mathrm{M})$, and (b,c,e,f) photocount-wavelength-decay profiles of (b) a PNC solution without $\mathrm{C}_{60}$, (c) a PNC solution with $4 \mu \mathrm{M} \mathrm{C}_{60}$, (e) a PNC film without $\mathrm{C}_{60}$ and (f) a PNC film with $4 \mu \mathrm{M} \mathrm{C}_{60}$.

Figure 3e,f. The fluorescence lifetime of a pristine PNC film is $4.2 \mu \mathrm{s}$, which in the presence of $4 \mu \mathrm{M} \mathrm{C}_{60}$ solution is decreased to 210 ns. Interestingly, the concentration of $\mathrm{C}_{60}$ needed for quantitative quenching of the excited state of PNC in a film sample was only one-half (1.4 wt\% of $\mathrm{C}_{60}$ with respect to PNC) of that needed for a solution sample. Yet another important observation is that the fluorescence lifetime of a PNC film without $\mathrm{C}_{60}(4.2 \mu \mathrm{s})$ is much longer than that of pristine PNC in the solution phase $(1.3 \mu \mathrm{s})$. The PL lifetime value of PNC films suggests that the electron diffusion length is in the same range as that of solution processed mixed halide perovskites, ${ }^{14 a}$ but longer than that for solution processed trihalide perovskites. ${ }^{14 \mathrm{~b}}$ These observations guide us to propose two hypotheses that may have important implications for perovskite-based electron transfer systems: (i) diffusion or migration of excitons by hopping among PNCs is promoted in close-packed film samples, which lowers the rate at which photo-generated charge carriers recombine, and (ii) $\mathrm{C}_{60}$ molecules doped in the film not only perturb exciton migration but also act as centers of non-radiative carrier recombination.

We correlate key results in this study with our hypothesis by coining a schematic presentation (Figure 4 ) of exciton migration among PNCs and electron transfer to $\mathrm{C}_{60}$. When dissolved in toluene, the capping ligand's octyl chains well-extend into the solvent, rendering PNCs isolated (Figure 4a). On the other hand, in the film state, the alkyl chains self-assemble by hydrophobic interactions (Figure 4b,c). Our assumption is that such a selfassembly promotes close-packing of PNCs and exciton diffusion in the films state (Figure 4b). In solution samples, the fluorescence intensity is decreased nearly quantitatively but without any change to the fluorescence lifetime, suggesting that adsorption of $\mathrm{C}_{60}$ molecules onto the hydrophobic-capped surface of a PNC leads to static and quantitative quenching of the excite state by electron transfer. Here, efficient trapping of electrons by $\mathrm{C}_{60}$ in the PNC- $\mathrm{C}_{60}$ composite does not allow us to retrieve any fluorescence from the composite. Thus, whatever fluorescence we detect at a given concentration of $\mathrm{C}_{60}$ in the PNC- $C_{60}$ mixture should originate from free PNCs, leaving fluorescence lifetime, but not intensity, $\mathrm{C}_{60}$-independent. With an increase in the concentration of $\mathrm{C}_{60}$, more and more PNCs adsorb one or more $\mathrm{C}_{60}$, and the overall fluorescence intensity of the solution decreases. In a film sample, exciton recombination is not limited to the point of generation because of the hole and electron migrations by hopping among closely-packed PNCs, making fluorescence lifetime unusually long when compared with that in a solution where PNCs are isolated. However, when the film is doped with $\mathrm{C}_{60}$, the migrating electrons can be trapped by $\mathrm{C}_{60}$, leading to fluorescence quenching. As the density of doped $\mathrm{C}_{60}$ increases, the area of exciton migration domain shrinks. When compared with isolated PNCs in a solution, which need at least one $\mathrm{C}_{60}$ per PNC for deactivation of the excited state, efficient quenching of fluorescence intensity and lifetime of films doped with low concentrations of $\mathrm{C}_{60}$ suggests that migrating excitons can be efficiently trapped by $\mathrm{C}_{60}$ sparsely doped in the film. Correlation between results and our hypothesis on exciton migration in a $\mathrm{FAPbBr}_{3} \mathrm{PNC}$ thin film and fluorescence quenching by electron transfer to $\mathrm{C}_{60}$ are presented in Figure 4.

In summary, the addition of $\mathrm{C}_{60}$ into a solution of hydrophobic-capped $\mathrm{FAPbBr}_{3} \mathrm{PNCs}$ results in the quantitative quenching PNC fluorescence, but without any change to the fluorescence lifetime. Such static quenching of fluorescence is credited to adsorption of $\mathrm{C}_{60}$ molecules onto the hydrophobic surface of NCs and efficient electron transfer from PNC to $\mathrm{C}_{60}$. When compared with pristine PNCs in a solution, their film shows unusually long fluorescence lifetime, indicating hopping or migration of photo-generated excitons among PNCs before radiative recombination. Both 


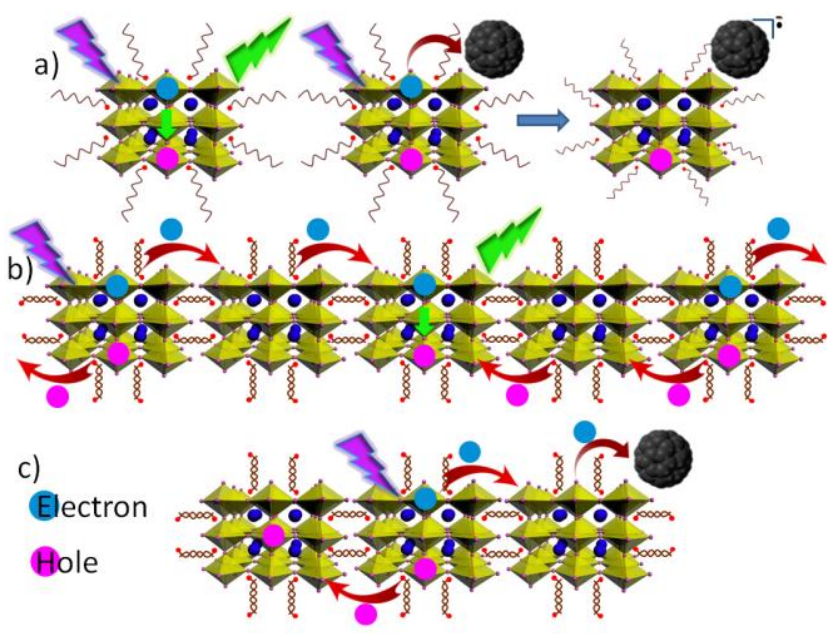

Figure 4. Schematic presentation of exciton dynamics in photoactivated $\mathrm{FAPbBr}_{3} \mathrm{PNC}$-fullerene composites: (a) fluorescence of PNCs and electron transfer to $\mathrm{C}_{60}$ in a solution, b) exciton migration in a PNC film, and (c) trapping of migrating exciton by $\mathrm{C}_{60}$ doped in a PNC film.

fluorescence intensity and lifetime of the PNC film monotonously decrease with increase in the doping density of $\mathrm{C}_{60}$, which is attributed to channeling of exciton migration into electron transfer to $\mathrm{C}_{60}$ molecules. Here $\mathrm{C}_{60}$ acts as an electron acceptor and center of non-radiative carrier recombination. Therefore, by analyzing steady-state and time-resolved fluorescence of highlyluminescent $\mathrm{FAPbBr}_{3}$ PNCs in the solution and films states, we successfully detect not only the diffusion of photo-generated excitons in films but also the restriction of exciton migration by electron transfer to $\mathrm{C}_{60}$ molecules doped in the film. Such migration of excitons and the channeling of exciton migration into electron transfer to $\mathrm{C}_{60}$ are promising for PNC sensitized solar cells.

\section{Acknowledgements}

VB and VCN acknowledge financial support from MEXT under the JSPS Grant-in-Aid for Scientific Research on Innovative Areas (Photosynergetics program Grant 15H01099). VCN thank DST for Ramanujan Fellowship (SR/S2/RJN-133/2012) and DST-SERI project (DST/TM/SERI/FR/121). C.M. is grateful to CSIR for a Research Fellowship. ALR acknowledges financial support from the Research Grant Council of Hong Kong S.A.R. (GRF project CityU 11337616).

Keywords: perovskite nanocrystals $\cdot$ exciton migration • fluorescence quenching $\bullet$ fullerene $\cdot$ electron transfer

[1] a) N. J. Jeon, J. H. Noh, W. S. Yang, Y. C. Kim, S. Ryu, J. Seo, S. Seok, Nature 2015, 517, 476-480; b) T. J. Jacobsson, J.-P. CorreaBaena, M. Pazoki, M. Saliba, K. Schenk, M. Grätzel, A. Hagfeldt, Energy Environ. Sci. 2016, 9, 1706-1724; c) X. Li, D. Bi, C. Yi, J.-D. Décoppet, J. Luo, S. M. Zakeeruddin, A. Hagfeldt, M. Grätzel, Science 2016, 353,58-62; d) A. Molina-Ontoria, I. Zimmermann, I. Garcia-Benito, P. Gratia, C. Roldan-Carmona, S. Aghazada, M. Graetzel, M. K.
Nazeeruddin, N. Martin, Angew. Chem. Int. Ed. 2016, 55, 6270 -6274 Angew. Chem. 2016, 128, 6378-6382.

[2] a) B. R. Sutherland, E. H. Sargent, Nat. photon. 2016, 10, 295-302; b) Q. Chen, N. D. Marco, Y. Yang, T.-B. Song, C.-C. Chen, H. Zhao, Z. Hong, H. Zhou, Y. Yang, Nano Today 2015, 10, 355-396; c) J. S. Manser, J. A. Christians, P. V. Kamat, Chem. Rev. DOI: 10.1021/acs.chemrev.6b00136; d) Y. Zhao, K. Zhu, Chem. Soc. Rev, 2016, 45, 655-689.

[3] a) L. C. Schmidt, A. Pertegás, S. González-Carrero, O. Malinkiewicz, S Agouram, G. M. Espallargas, H. J. Bolink, R. E. Galian, J. Pérez-Prieto, J. Am. Chem. Soc. 2014, 136, 850-853; b) A. Pan, B. He, X. Fan, Z Liu, J. J. Urban, A. P. Alivisatos, L. He, Y. Liu, ACS Nano 2016, 10 7943-7954; c) H.-C. Wang, S.-Y. Lin, A.-C. Tang, B. P. Singh, H.-C. Tong, C.-Y. Chen, Y.-C. Lee, T.-L. Tsai, R.-S. Liu, Angew. Chem. Int. Ed. 2016, 55, 7924 -7929; Angew. Chem. 2016, 128, 8056-8061; d) B. Luo, Y.-C. Pu, S. A. Lindley, Y. Yang, L. Lu, Y. Li, X. Li, J. Z. Zhang, Angew. Chem. Int. Ed. 2016, 55, 8864 -8868; Angew. Chem. 2016, 128, 9010-9014; e) Y. Hassan, Y. Song, R. D. Pensack, A. I. Abdelrahman, Y. Kobayashi, M. A. Winnik, G. D. Scholes, Adv. Mater. 2016, 28, 566-573.

[4] a) H. Huang, A. S. Susha, S. V. Kershaw, T. F. Hung, A. L. Rogach, Adv. Sci. 2015, 2, DOI: 10.1002/advs.201500194; b) F. Zhang, H. Zhong, C. Chen, X.-g. Wu, X. Hu, H. Huang, J. Han, B. Zou, Y. Dong ACS Nano 2015, 9, 4533-4542; c) J. A. Sichert, Y. Tong, N. Mutz, M. Vollmer, S. Fischer, K, Z. Milowska, R. G. Cortadella, B. Nickel, C Cardenas-Daw, J. K. Stolarczyk, A. S. Urban, J. Feldmann, Nano Lett. 2015, 15, 6521-6527; d) P. Kumar, C. Muthu, V. C. Nair, K. S. Narayan, J. Phys. Chem. C 2016, 120, 18333-18339; e) D. M. Jang, K. Park, D. H. Kim, J. Park, F. Shojaei, H. S. Kang, J.-P. Ahn, J. W. Lee, J. K. Song, Nano Lett. 2015, 15, 5191-5199.

[5] a) S. S. Mali, C. S. Shim, C. K. Hong, NPG Asia Mater. 2015, 7 , doi:10.1038/am.2015.86; b) S. Dastidar, D. A. Egger, L. Z. Tan, S. B. Cromer, A. D. Dillon, S. Liu, L. Kronik, A. M. Rappe, A. T. Fafarman, Nano Lett. 2016, 16, 3563-3570; c) Y. Ling, Z. Yuan, Y. Tian, X. Wang, J. C. Wang, Y. Xin, K. Hanson, B. Ma, H. Gao, Adv. Mater. 2016, 28 305-311; d) G. Li, F. W. R. Rivarola, N. J. L. K. Davis, S. Bai, T. C. Jellicoe, F. Peña, S. Hou, C. Ducati, F. Gao, R. H. Friend, N. C. Greenham, Z.-K. Tan, Adv. Mater. 2016, 28, 3528-3534; e) G. Li, Z.-K. Tan, D. Di, M. L. Lai, L. Jiang, J. H.-W. Lim, R. H. Friend, N. C. Greenham, Nano Lett. 2015, 15, 2640-2644; f) X. Zhang, H. Lin, H. Huang, C. Reckmeier, Y. Zhang, W. C. H. Choy, A. L. Rogach, Nano Lett. 2016, 16, 1415-1420; g) C. Muthu, S. Agarwal, A. Vijayan, P Hazra, K. B. Jinesh, V. C. Nair, Adv. Mater. Interfaces 2016, DOI: 10.1002/admi.201600092.

[6] a) J. lehl, J.-F. Nierengarten, A. Harriman, T. Bura, R. Ziessel, J. Am. Chem.Soc. 2012, 134, 988-998; b) M. Rudolf, S. V. Kirner, D. M. Guldi, Chem. Soc. Rev. 2016, 45, 612-630; c) F. Wang, X. Liu, I. Willner, Adv. Mater. 2013, 25, 349-377; d) S. Fukuzumi, K. Ohkubo, T. Suenobu, Acc. Chem. Res. 2014, 47, 1455-1464.

[7] A. Marchioro, J. Teuscher, D. Friedrich, M. Kunst, R. Krol, T. Moehl, M. Gratzel, J.-E. Moser, Nature 2014, 8, 250-255.

[8] C. S. Ponseca Jr., E. M. Hutter, P. Piatkowski, B. Cohen, T. Pascher, A. Douhal, A. Yartsev, V. Sundström, T. J. Savenije, J. Am. Chem. Soc. 2015, 137, 16043-16048.

[9] K. Wu, G. Liang, Q. Shang, Y. Ren, D. Kong, T. Lian, J. Am. Chem Soc. 2015, 137, 12792-12795

[10] R. Zhu, C. Gao, T. Sun, L. Shen, D. Sun, X. Li, Langmuir 2016, 32 3294-3299

[11] Y. Shao, Z. Xiao, C. Bi, Y. Yuan, J. Huang, Nat. Commun. 2014, 5 , 5784.

[12] J. Xu, A. Buin, Alexander H. Ip, W. Li, O. Voznyy, R. Comin, M. Yuan, S. Jeon, Z. Ning, J. J. McDowell1, P. Kanjanaboos, J.-P. Sun, X. Lan, L. N. Quan, D. H. Kim, I. G. Hill, P. Maksymovych, E. H. Sargent, Nat. Commun. 2015, 6, 7081.

[13] a) R. Ding, H. Liu, X. Zhang, J. Xiao, R. Kishor, H. Sun, B. Zhu, G. Chen, F. Gao, X. Feng, J. Chen, X. Chen, X. Sun, Y. Zheng, Adv. Funct. 
Mater. 2016, DOI: 10.1002/adfm.201602634; b) M. F. Aygüler, M. D. Weber, B. M. D. Puscher, D. D. Medina, P. Docampo, R. D. Costa, J. Phys. Chem. C 2015, 119, 12047-12054; c) Y. Fu, H. Zhu, A. W Schrader, D. Liang, Q. Ding, P. Joshi, L. Hwang, X-Y. Zhu, S. Jin, Nano Lett. 2016, 16, 1000-1008; d) A. A. Zhumekenov, M. I. Saidaminov, M. A. Haque, E. Alarousu, S. P. Sarmah, B. Murali, I. Dursun, X-H Miao, A L. Abdelhady, T. Wu, O. F. Mohammed, O. M. Bakr, ACS Energy Lett. 2016, 1, 32-37; e) G. E. Eperon, S. D. Stranks, C. Menelaou, M. B Johnston, L. M. Herz, H. J. Snaith, Energy Environ. Sci. 2014, 7, 982988

14. a) S. D. Stranks, G. E. Eperon, G. Grancini, C. Menelaou, M. J. P. Alcocer T. Leijtens, L. M. Herz, A. Petrozza, H. J. Snaith, Science 2013, 342 341-344; b) G. Xing, N. Mathews, S. Sun, S. S. Lim, Y. M. Lam, M. Grätzel, S. Mhaisalkar, T. C. Sum, Science 2013, 342, 344-347. 


\section{Entry for the Table of Contents}

\section{COMMUNICATION}

Exciton migration among closely-packed formamidinium lead bromide perovskite nanocrystals in thin films extends their fluorescence lifetime. By doping the film with $\mathrm{C}_{60}$ molecules, we efficiently trap migrating excitons, which quantitatively quenches the fluorescence of the nanocrystals. Trapping of delocalized charge carriers using well-defined electron acceptors in a thin film of perovskite nanocrystals is expected to have great impact on photovoltaic technology.

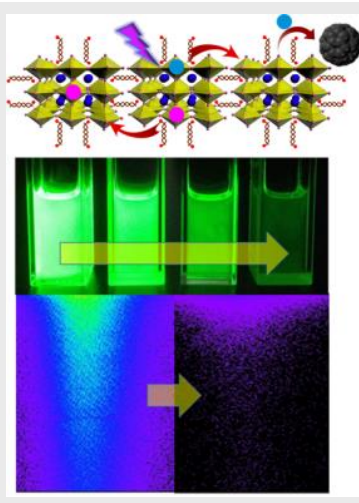

Vijayakumar C. Nair* Chinnadural Muthu, Andrey L. Rogach, Reiko Kohara, Vasudevanpillai Biju*

Page No. - Page No.

Channeling Exciton Migration into Electron Transfer in Formamidinium Lead Bromide Perovskite Nanocrystal / Fullerene Composites 